\title{
Therapeutic targeting in nanomedicine: the future lies in recombinant antibodies
}

The unique chemical and functional properties of nanoparticles can be harnessed for the delivery of large quantities of various therapeutic biomolecules. Active targeting of nanoparticles by conjugating ligands that bind to target cells strongly facilitates accumulation, internalization into target cells and longer retention at the target site, with consequent enhanced therapeutic effects. Recombinant antibodies with high selectivity and availability for a vast range of targets will dominate the future. In this review, we systematically outline the tremendous progress in the conjugation of antibodies to nanoparticles and the clear advantages that recombinant antibodies offer in the therapeutic targeting of nanoparticles. The demonstrated flexibility of recombinant antibody coupling to nanoparticles highlights the bright future of this technology for modern therapeutic nanomedicine.

First draft submitted: 2 February 2017; Accepted for publication: 7 June 2017; Published online: 13 July 2017

Keywords: active targeting $\bullet$ antibody targeting $\bullet$ cancer therapy $\bullet$ drug delivery - nanomedicine $\bullet$ nanoparticles $\bullet$ passive targeting $\bullet$ recombinant antibody $\bullet$ single-chain antibody

In the last decade, there has been a surge of interest in nanomedicine, the application of nanotechnologies and nanomaterials for the diagnosis and treatment of human disease [1]. Nanoparticles are the main drivers in a majority of applications in nanomedicine [2]. Nanoparticles are particles in the size range of 1-100 nm. Metallic nanoparticles have different physicochemical and optical properties compared with their larger counterparts due to quantum effects. These properties can be harnessed for various applications including biosensors for measuring disease biomarkers, drug-delivery systems, imaging agents and nanomachines. Nanoparticles are small enough to be in the size range of biological molecules and smaller than cells, which therefore makes them ideal for delivering various cargoes into cells. For biomedical applications, in vivo properties such as size, charge, biocompatibility and absence of toxicity are paramount [3]. The circulation half-life of nanoparticles is dependent on a number of characteristics such as size, charge, surface property and composition [4]. The nanoparticles have to be large enough to avoid clearance through the kidney via urine $(>10 \mathrm{~nm})$ and small enough $(<200 \mathrm{~nm})$ to avoid uptake by cells of the reticuloendothelial system $[5,6]$. Surface modification of the nanoparticles with amphiphillic polymers minimizes uptake by the reticuloendothelial system (RES), liver and spleen. The large surface-to-volume ratio of nanoparticles engenders them with a high-loading capacity for delivery of therapeutic or imaging agents. The tunability of nanoparticles, their ability to take on specific biophysical and biocompatible properties during or after manufacturing by surface biofunctionalization, allows them further versatile uses in biomedicine.
Geoffrey A Pietersz**,1,2,3,4, Xiaowei Wang1,5, May Lin Yap ${ }^{1,4}$, Bock Lim \& Karlheinz Peter $*, 1,2,5$

'Baker IDI Heart \& Diabetes Institute, Melbourne, Australia

Department of Immunology, Monash University, Melbourne, Australia ${ }^{3}$ Burnet Institute, Centre for Biomedical Research, Melbourne, Australia ${ }^{4}$ Department of Pathology, University of Melbourne, Melbourne, Australia ${ }^{5}$ Department of Medicine, Monash University, Melbourne, Australia *Author for correspondence: Karlheinz.Peter@bakeridi.edu.au **Author for correspondence: Geoff.pietersz@burnet.edu.au 
Nanoparticulate biomaterials can be divided into two broad classes: inorganic and organic. Inorganic nanoparticles consist of metallic ( $\mathrm{Au}, \mathrm{Ag}$ and $\mathrm{Cu}$ ) [7], magnetic $\left(\mathrm{Fe}_{3} \mathrm{O}_{4}\right.$ and $\left.\gamma \mathrm{Fe}_{2} \mathrm{O}_{3}\right)$ [8], quantum dots $(\mathrm{CdSe} / \mathrm{ZnS}$ and $\mathrm{CdTe} / \mathrm{CdS})$ [9] and silica [10] particles. Organic nanoparticles include those made of synthetic polymers/co-polymers [11], dendrimers [12], proteins [13], lipids [14], carbon nanotubes [15] or natural carbohydrates [16]. Biocompatibility and biodegradability make organic nanoparticles ideal for drug delivery, but they do not have the tunability of metallic inorganic nanoparticles. However, combinations of inorganic and organic material to generate hybrid nanoparticles introduce versatility, with multifunctionality and improved stability.

Notably, nontargeted nanoparticles have only rarely offered convincing advantages that have resulted in clinical applications. The first therapeutic nanoparticle composition for systemic use based on a polyethylene glycol (PEG)-modified liposome-entrapped doxorubicin (Doxil ${ }^{\circledR}$, Janssen Biotech, Inc. PA, USA) was approved by the US FDA in 1995, followed by DaunoXome $^{\circledR}$ (daunorubicin liposome formulation, Galen Limited, Craigavon, UK), Marqibo ${ }^{\circledR}$ (vincristine liposome formulation, Spectrum Pharmaceuticles, NV, USA) and more recently Onivyde ${ }^{\circledR}$ (irinotecan liposome formulation, Ipsen Biopharmaceuticles, NJ, USA) in $2015[17,18]$. The only nonliposomal nanoparticle formulation approved by the FDA is Abraxane ${ }^{\circledR}$ (Abraxis BioScience, CA, USA), an albumin-bound paclitaxel formulation. The following review discusses the progress and benefits but also the challenges associated with targeting of nanoparticles, particularly with recombinant antibodies.

\section{Targeting of nanoparticles}

There are two ways that nanoparticles can target tumors: passively and actively. Passive targeting takes advantage of the leaky vasculature of tumors. Unlike normal blood vessels, the blood vessels of tumors have gaps or fenestrations at the borders of endothelial cells and also lack smooth muscle. In addition, the lymphatic drainage of tumors is also ineffective. These properties, which distinguish tumor from normal tissue, allow enriching of nanoparticles at tumor sites due to an enhanced permeation and retention (EPR) effect [19]. Active targeting utilizes ligands attached to the surface of the nanoparticle, which can bind molecular structures or antigens that are overexpressed or preferentially present at the tumor site [20-22]. Nanoparticles targeted by the EPR effect are localized in the interstitial spaces of the tumor, with no specific tumor cell internalizing mechanism, while ligand-targeted nanoparticles bind to cell surface receptors and are internalized by receptor-mediated endocytosis. Therefore, active targeting increases the uptake of nanoparticles and their cargo into the target tumor cells. A variety of different molecules have been used for biofunctionalization of nanoparticles for active targeting including antibodies [23], affibodies [24], peptides [25], aptamers [26], carbohydrates [27] and small chemical entities such as receptor ligands [23]. In this review, we highlight the use of monoclonal antibodies for active targeting, with an emphasis on recombinant antibodies.

\section{Therapeutic nanoparticles}

For therapeutic purposes, nanoparticles may carry a therapeutic cargo for direct killing of target cells by inhibiting a biochemical target involved in cell proliferation, such as DNA or RNA synthesis, tubulin polymerization or silencing genes. Alternatively, nanoparticles can carry tumor-associated antigens in order to induce an antitumor immune response. In addition, external magnetic fields or laser irradiation can induce local hyperthermia at tumor sites targeted with stimuli-responsive nanoparticles. These approaches have been extensively reviewed previously.

\section{Drug-loaded nanoparticles}

For drug delivery, the drugs may be uniformly dispersed in the matrix of a nanosphere, confined to a cavity inside a nanocapsule or adsorbed/linked on the surface $[28,29]$. Such incorporation assists in drug solubilization, reduces rapid clearance of the drugs from circulation and protects the drugs from degradation. Once localized at the tumor site by the EPR effect, the nanoparticles can release the drug by diffusion or degradation depending on the biomaterial. In addition to localized delivery of therapeutic cargo to the tumor site, inherent properties of the nanomaterial can be utilized for further selectivity (see below).

\section{SiRNA}

siRNAs confer a therapeutic effect by silencing genes involved in tumor progression or survival by knockdown of mRNA. siRNAs are 19-21 nucleotide negatively charged molecules that are rapidly degraded by serum RNAses and cleared by renal excretion, and can be immunotoxic, for example, by release of cytokines via binding to toll-like receptors. For these reasons, nanocarrier design for siRNA has been an active area of research [30-33]. For effective knockdown, siRNA molecules have to be internalized into cells and enter the cytoplasm. siRNA-loaded nanoparticles taken up by an endocytic mechanism will need to escape the endosomal compartment or else they will be degraded in the lysosomes. Various strategies to facilitate endosomal escape have been developed [34]. Nanoparticles 
based on cationic lipids are most widely used for siRNA delivery.

\section{Nanoparticulate vaccines}

Nanoparticle vaccines mobilize the immune system to destroy malignant tissue by means of generating tumor antigen-specific $T$ cells or antibodies [35,36]. Dendritic cells are the sentinels of the immune system that take up antigen and degrade it in the antigen-processing compartment. Dendritic cells express several C-type lectin receptors (CD205, CD206 and CD209), which have been targeted by antigen-loaded nanoparticles for vaccination [37,38]. The peptides from degraded antigen are loaded into MHC class I molecules in the endoplasmic reticulum and presented on the surface of the antigen-presenting cell-to-T-cell receptors on CD8 $T$ cells to prime antigen-specific $T$ cells. Nanoparticle size, charge and material influence the quality and type of the immune response [39].

\section{Stimuli-responsive nanoparticles}

Ideally the therapeutic effect of the nanoparticle cargo should only be a deleterious impact on the tumor, while sparing healthy tissue in order to avoid side effects. To improve such specificity, nanoparticles that can be triggered to release their cargo and induce their therapeutic effect by an endogenous or exogenous stimulus have been designed. The exogenous stimuli include magnetic fields [40], light [26,41-43], temperature and ultrasound [44], which can be applied spatiotemporally at the target site. Superparamagnetic iron oxide (SPIO) nanoparticles, in addition to their use as a contrast agent in MRI, can be used for drug delivery assisted by magnetic field guidance, as well as for generating local hyperthermia by use of an alternating magnetic field. Cancer cells are susceptible to hyperthermia (42$43^{\circ} \mathrm{C}$ ) due to their inefficient dissipation of heat as a result of inefficient blood flow and oxygen transport. Many inorganic nanoparticles of gold (nanospheres, nanorods, nanoshells and nanocages), carbon (graphene and single- or multi-walled carbon nanotubes), silver, transition metal oxides and sulfides can convert absorbed light into heat. Visible and UV light-absorbing molecules, such as hemoglobin and melanin, hinder the use of visible and UV light as external stimuli. However, near-infrared light (NIR) of wavelengths 650-900 $\mathrm{nm}$ has maximal depth of tissue penetration and is frequently used. On irradiation with electromagnetic radiation, electrons in nanoscale gold particles coherently oscillate at a specific frequency, which results in strong absorption and scattering known as surface plasmon resonance (SPR). This frequency is dependent on the size and shape of the nanoparticle. The gold nanospheres are not useful for in vivo applications due to the SPR at $520 \mathrm{~nm}$ in the visible region. However, the SPR of the gold nanostructures can be tuned to NIR based on the size, shape or thickness of the shell. Gold nanorods of different aspect ratios with a constant width and variable lengths can be readily synthesized. These have a transverse SPR at $515-520 \mathrm{~nm}$ and a tunable localized SPR in NIR based on length from $\sim 680$ to $\sim 1100 \mathrm{~nm}$. Irradiation of these gold particles at their localized SPR results in efficient conversion to heat for targeted cell and tissue destruction. Similar to magnetic fields, lasers can also be specifically placed for local irradiation of tumors.

The unique properties of the tumor microenvironment can be utilized to increase the selectivity of passive targeting of stimuli-responsive nanoparticles via the EPR effect. Restricted blood flow in the tumor surroundings can result in hypoxia and reduced $\mathrm{pH}$, and provides a reducing environment rich in proteolytic enzymes. A myriad of different polymeric nanoparticles has been designed incorporating single or multiple chemically responsive or enzymatically responsive linkages that can be used for targeted drug release. Polymeric nanoparticles incorporating acetals, disulfides and peptides substrates for $\mathrm{pH}$ reduction and enzymatic stimuli (Cathepsin B and Matrix metalloproteinases) [45-51] have been used successfully.

As described previously, the above nanoparticles accumulate in tumor due to the EPR effect. By utilizing stimuli-responsive nanoparticles selectivity and/or specificity can be gained. One of the disadvantages of these particles is the difficulty to precisely determine the optimal time for applying the stimulus - be it light or an electromagnetic field. Having a theranostic reagent to ascertain optimal timing will aid in such targeting strategies. Nanoparticles incorporating a targeting ligand still have to extravasate into the tumor by the EPR effect and its uptake by EPR is positively correlated with circulation time [52]. Many studies have demonstrated that the inclusion of a targeting ligand does not direct the nanoparticle to the tumor but aids in the internalization and accumulation in the tumor [53]. Several studies have also shown that targeted nanoparticles have higher tumor uptake and greater efficacy than nontargeted nanoparticles (Table 1). A comprehensive survey of the literature from the past 10 years indicated that only $0.7 \%$ (median) of the injected dose of nanoparticles was delivered to the tumor [54]. Active targeting strategies had a higher delivery efficiency of $0.9 \%$ than passive targeting $(0.6 \%)$ approaches. Other advantages of antibody-mediated targeting are the possibility of using multiple antibodies to overcome tumor heterogeneity and avoid drug efflux to overcome multidrug resistance [55]. Furthermore, targeted nanoparticles are essential for imaging thrombi, for effective 
Table 1. Summary of preclinical studies with various recombinant antibody-targeted nanoparticles.

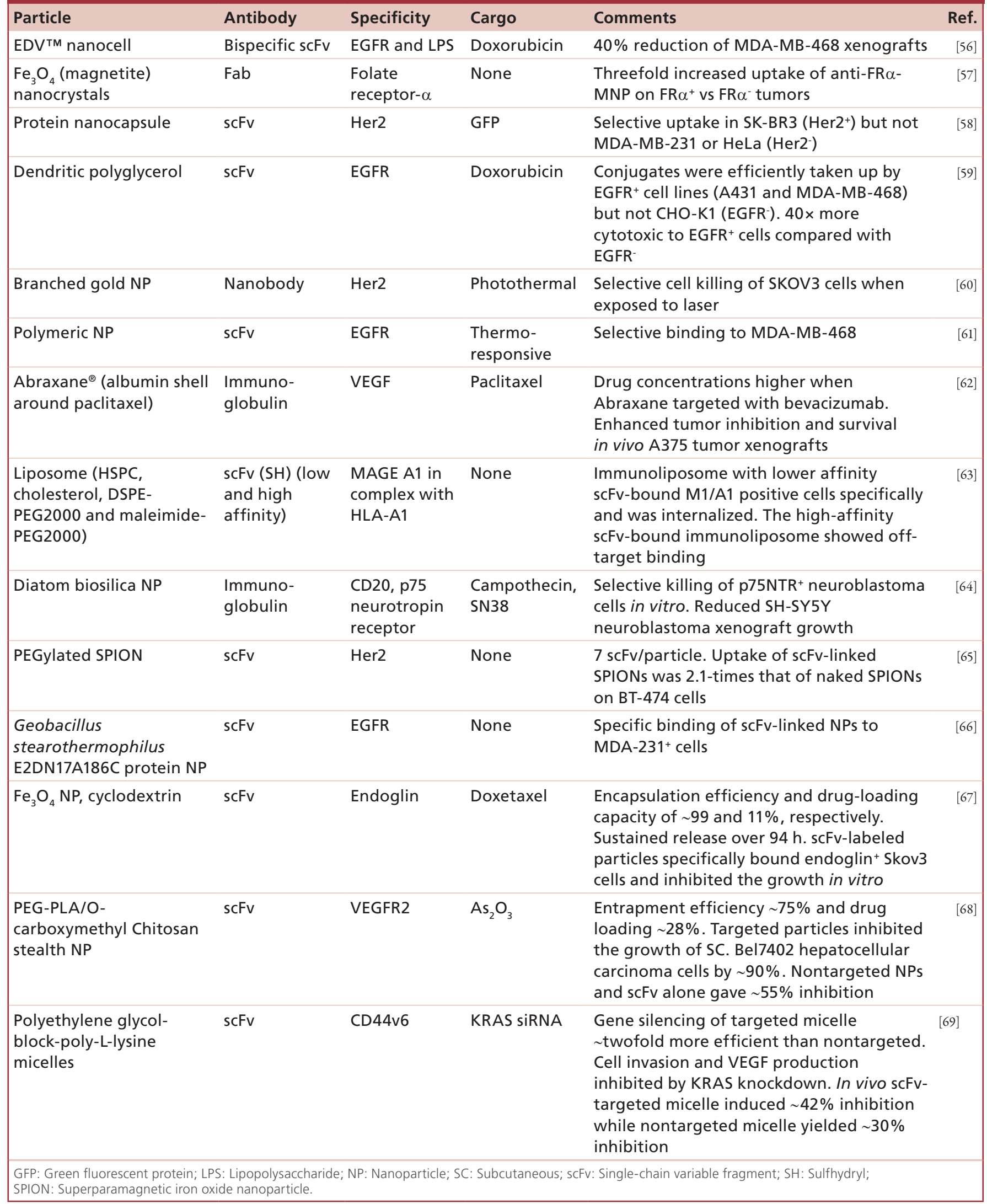


Table 1. Summary of preclinical studies with various recombinant antibody-targeted nanoparticles (cont.).

\begin{tabular}{|c|c|c|c|c|c|}
\hline Particle & Antibody & Specificity & Cargo & Comments & Ref. \\
\hline $\begin{array}{l}\text { Polyethylene glycol- } \\
\text { block-poly(D,L-lactide) NP }\end{array}$ & scFv & Her2 & $\begin{array}{l}\text { Polo-like } \\
\text { kinase siRNA }\end{array}$ & $\begin{array}{l}\text { Fluorescence imaging indicated } \sim \text { twofold } \\
\text { more uptake of siRNA in tumor when } \\
\text { targeted. Targeted siRNA NPs were more } \\
\text { inhibitory in vivo on BT474 (Her2+) but of } \\
\text { similar inhibitory activity on MDA-MB- } \\
231 \text { (Her2) xenografts. In dose response } \\
\text { studies, targeted siRNA NPs were more } \\
\text { effective at lower doses on BT474 cells }\end{array}$ & {$[70]$} \\
\hline $\begin{array}{l}\text { Polyethylene glycol- } \\
\text { block-poly(D,L-lactide) NP }\end{array}$ & scFv & CD44v6 & $\mathrm{As}_{2} \mathrm{O}_{3}$ & $\begin{array}{l}\text { Targeted NPs accumulated in PANC- } \\
1 \text { xenografts at level } \sim \text { twice that of } \\
\text { nontargeted. Tumor inhibition } \sim 85 \% \text { in } \\
\text { mice treated with targeted NPs compared } \\
\text { with control while } \sim 60 \% \text { in mice treated } \\
\text { with nontargeted NPs }\end{array}$ & {$[71]$} \\
\hline $\begin{array}{l}\text { Heparin (succinic } \\
\text { anhydride-modified) }\end{array}$ & scFv & EGFR & Cisplatin & $\begin{array}{l}50 \% \text { drug release in } 72 \mathrm{~h} \text {. In biodistribution } \\
\text { studies, Pt levels at } 4 \mathrm{~h} \text { as detected by } \\
\text { ICP-MS in H292 tumors of mice treated } \\
\text { with scFv-linked was twofold higher than } \\
\text { those injected with naked particles and } \\
\text { was sustained longer. Antitumor effect of } \\
\text { targeted NPs was significantly greater than } \\
\text { nontargeted with lower kidney and spleen } \\
\text { toxicity than free cisplatin }\end{array}$ & {$[73]$} \\
\hline
\end{tabular}

thrombolysis or antiplatelet therapy without bleeding. One of the disadvantages of conjugation of antibodies to nanoparticles is the possible introduction of heterogeneity that may hinder reproducible manufacture for clinical studies. As discussed below recombinant antibodies and novel site-specific conjugation strategies may overcome these issues.

\section{Recombinant antibodies and fragments}

Antibody development has come a long way since the advent of the hybridoma technology by Köhler and Milstein in 1975 [74]. The first FDA-approved murine therapeutic antibody, OKT3 in 1986, was used in immunosuppression for patients after transplants. However, the use of murine antibodies in humans revealed severe limitations such as short serum halflife, immunogenicity and inefficient triggering of the human effector system. With the advent of genetic engineering techniques, chimeric antibodies that consist of murine variable chain regions grafted onto a human constant region were designed (Figure 1). Chimeric antibodies were still immunogenic in humans, albeit at lower levels, but several of these were approved by the FDA, notably Rituximab for B-cell non-Hodgkin lymphoma. Further modifications were then made to enhance the humanization of murine antibodies via replacement of the complementarity-determining regions (CDRs) of a human antibody framework with murine CDRs. Frequently, such a process results in the loss of some binding affinity and required some mutagenesis to the constant regions adjacent to the CDRs. Currently, human antibodies are derived by screening human phage display libraries or immunization of transgenic mice expressing only human heavy and light chain antibody genes. Recent data on antiproprotein convertase subtilisin-kexin type 9 (PCSK9) binding antibodies notably indicate that fully human antibodies clearly have advantages compared with mouse antibodies, even those that have been highly humanized [75,76]. Trials with chronic application of 
the latter type of antibody, bococizumab, were stopped prematurely after the sponsor elected to discontinue the development of bococizumab, owing in part to the development of high rates of antidrug antibodies [75]. This phenomenon occurred although only $3 \%$ of the overall antibody remained of the murine sequence. In contrast, the antibody evolocumab, derived from human sequences, did not result in relevant antidrug antibody development and revealed a positive outcome in regard to the reduction of cardiovascular events [76].

As of mid-2016, more than 62 therapeutic antibodies have been approved for human use [36,77-78]. In addition, the antibody-drug conjugates (ADC) Kadcyla $^{\circledR}$ (trastuzumab emtansine, Genentech, CA, USA) and Adcetris ${ }^{\circledR}$ (brentuximab vedotin, Seattle Genetics, Inc., WA, USA) were approved by the FDA in 2013 and 2011 for Her2-positive patients and CD30 ${ }^{+}$ Hodgkin lymphoma, respectively. The ADC Mylo$\operatorname{targ}^{\circledR}$ (gemtuzumab ozogamicin, Wyeth Laboratories, PA, USA) was approved by the FDA in 2000 for patients $>60$ years with acute myeloid leukemia, but was retracted in 2010. Genetic engineering techniques have allowed customization of antibody molecules with modified carbohydrate moieties and mutated $\mathrm{Fc}_{\mathrm{C}}$ in order to modulate $\mathrm{Fc}_{\mathrm{C}}$ receptor or complement binding, and to increase in vivo half-life [79]. In addition, recombinant antibody fragments of various sizes and shapes with the antigen-binding moiety, variable heavy and variable light chain (VH and VL, respectively) to alter size and monovalent/multivalent binding have been engineered (Figure 1). As discussed below, these smaller antibody fragments are readily amenable to modification with single amino acids or sequences in order to allow site-specific attachment of nanoparticles.

\section{Linkage of monoclonal antibodies to nanoparticles}

Crucial for successful targeting is the stable conjugation of the antibody to the nanoparticle, taking particular care to avoid aggregate formation. For conjugation, a suitable functional group has to be introduced onto the nanoparticle surface or the antibody (Figure 2). A number of reactive groups on amino acids of antibodies can be used for conjugation: amino (lysine), carboxy (glutamic and aspartic acids), cysteine (via reduction of cystines) and carbohydrate (via periodate oxidation of cis-diols to aldehydes). Reactive groups can be introduced onto nanoparticles either noncovalently by adsorption/coating with suitably functionalized polymers, by covalent linkage of polymers, or, as in the case of gold nanoparticles, with bifunctional thiols because of their inherent affinity for thiols. A large body of work in the area of bioconjugation of anti- bodies to nanoparticles has been published. We only briefly discuss some aspects of chemical strategies as far as they are utilized with recombinant antibodies and their fragments. As noted below, these modifications on antibodies in most cases are random and difficult to control, leading to heterogeneity and potential loss of antibody-binding activity.

\section{Carboxylic acid: amides}

The amide linkage is a stable linkage formed on condensation of a carboxylic acid with an amine, frequently with the use of water-soluble carbodiimides such as 1-ethyl-3-(3-dimethylaminopropyl)carbodiimide (EDCI) (Figure 2A). Since antibodies contain amino groups (lysine), as well as carboxylic acid groups (glutamic and aspartic acid), this is best performed as a two-step reaction in order to prevent intramolecular and intermolecular cross-linking of the antibody [80]. Carboxylic acids are introduced onto the nanoparticles by surface modification, and active esters are made first with the use of N-hydroxysuccinimide (NHS) or sulfo-NHS and EDCI (Figure 2B). The active ester intermediate is then reacted with the amino groups of the antibody. Pre-activation of carboxylic acids on the nanoparticle will reduce the aggregation of antibodies. However, the antibody could still attach via one or more random amino groups or attach to multiple nanoparticles, and therefore needs careful optimization [81].

\section{Amines: Schiff base linkage}

Amine groups on nanoparticles may be cross-linked to amino groups of lysine on antibodies using glutaraldehyde (Figure 2C). However, if performed in a one-pot reaction, it leads to aggregation due to intramolecular and intermolecular linkage between antibodies or nanoparticles. Pre-activation of particles with glutaraldehyde and removal of excess reagent before reacting with antibodies will reduce aggregation. Poly(lactide)co-glycolide-PEG amine diblock polymer nanoparticles loaded with gemcidabine were conjugated to anti-EGFR antibodies via a two-step conjugation procedure [82]. The antibody-conjugated nanoparticles were internalized by EGFR ${ }^{+}$MIA PaCa- 2 cells and showed a twofold selectivity compared with naked particles. An increased polydispersity index suggested some cross-linking between the nanoparticles. Amines on nanoparticles or antibodies readily react with active esters, and many commercially available heterobifunctional cross-linking agents with an NHS ester and a variety of other functional groups (e.g., acids, alkynes, azides, maleimides and pyridyldithio) are used for modification of an amino group of an antibody to another functional group for conjugation. 


\section{Aldehydes: hydrazone}

Carbohydrate residues in the hinge region $(\mathrm{CH} 2)$ of antibodies can be used for site-specific modification. Mild oxidation of vicinal hydroxyl groups of sialic acid or mannose residues results in aldehyde residues that can be modified with homo- or heterobifunctional cross-linking agents that have a hydrazide group, to form a hydrazone. Stable hydrazone formation is favored at an acidic $\mathrm{pH}(\mathrm{pH} \sim 5)$. Antibodies modified with hydrazide-PEG-dithiol or dithiolalkanearomaticPEG6-NHNH2 can be directly linked to gold nanorods [83,84]. The aldehydes formed can also be used to covalently modify amine-containing nanoparticles to form a Schiff base linkage. However, these bonds are unstable and require reduction with sodium borohydride or sodium cyanoborohydride to form secondary amines. An advantage of the conjugation of antibodies via the Fc region carbohydrate is that the antibody is specifically orientated on the nanoparticle at a site distant from the antibody-binding site. Furthermore, use of a heterobifunctional cross-linker with a hydrazide group and an azide, alkyne, maleimide or pyridyldithio group allows versatility to link to a variety of functionalized nanoparticles.

\section{Thiol: disulfide/thioether}

Thiols on a nanoparticle or antibody can react with a pyridyldithio group (activated thiol) or a maleimide to form a disulfide (Figure 2D) or thioether (Figure 2E) linkage, respectively. Thiol groups introduced using heterobifunctional reagents into antibodies or exposed by reduction of intraheavy chain disulfides of intact antibodies can be directly linked to the surface of gold nanoparticles. Maleimide-functionalized lipids are frequently used to conjugate lipidic nanoparticles to thiolated antibodies. Zhai et al. used maleimidefunctionalized, phytantriol-based liquid-crystalline nanoparticles to link anti-EGFR Fab' fragments [14]. Conjugation efficiencies of $95-99 \%$ were observed without an effect on the size of the particles and a slight decrease in antibody-binding affinity. Careful optimization of the reduction of the interheavy chain disulfide is a site-selective modification and has been utilized for attachment of other functional groups. Reaction of the maleimide aza-dibenzocyclooctyne-PEG4-maleimide with the sulfhydryl groups of reduced anti-Her2 antibody introduced 3-4 aza-dibenzocyclooctyne groups, which facilitated conjugation of azide-functionalized silica nanoparticles via a click reaction (see below) [85].

\section{Click reaction}

The click reaction is an intermolecular cyclization reaction combining an azide with an alkyne, resulting in a stable, inert 1,2,3-triazole linkage between two macromolecules (Figure 2F). These copper-catalyzed azide-alkyne cycloadditions (CuAAC) can be conducted under mild reaction conditions in aqueous solution. However, $\mathrm{Cu}(\mathrm{I})$ can generate reactive oxygen species and interact with biomolecules. Finetti et al. used an alkyne functionalized polymer to coat and stabilize gold nanoparticles, which were subsequently conjugated to azide-functionalized anti-CD63 antibodies [86]. Alternatively, Cu-free strain-promoted azide-alkyne click (SPAAC) chemistry can be used with biomolecules or nanoparticles functionalized with 1,4-diazabicyclo [2.2.2] octane (DABCO) or bicyclo [6.1.0] non-4-yne (BCN) groups without the requirement for copper catalysis (Figure 2G). Jeong et al. demonstrated the superior antigen-binding capacity of anti-Her2 linked to silica nanoparticles by a site-selective click reaction, compared with conjugation via EDCI/NHS [85]. Conjugation via click reaction achieved efficiencies of 50-70\% compared with $1-20 \%$ by EDCI/NHS. Quantitative analysis indicated that almost all antibody molecules linked site specifically to the nanoparticle-bound antigen, while only $1 / 8$ of the antibody molecules randomly linked to the nanoparticle-bound antigen [85]. Another bioorthogonal reaction with fast reaction rates is the DielsAlder cycloaddition between a trans-cyclooctene and tetrazines [87].

\section{Specific conjugation strategies with recombinant antibodies}

The various strategies for conjugating antibodies described above are not site specific. Such conjugation procedures risk aggregate formation and no optimum orientation of the antibody on the nanoparticle surface, which could result in a loss of binding. The use of recombinant antibodies and fusion proteins allows strategies that overcome these deficiencies (Figure 3).

\section{Genetic fusion}

\section{Streptavidin/biotin}

The high-affinity noncovalent interaction (Kd $\sim 10$ ${ }^{15}$ ) of avidin or streptavidin with biotin has been utilized for nanoparticle bioconjugation to single-chain antibodies. The Escherichia coli biotin ligase (BirA) biotinylates a 15 amino acid peptide (AviTag'TM, Avidity LLC, CO, USA), which can be incorporated for genetic fusion to a variety of proteins for site-specific labeling. AviTag was fused to a single-chain antibody recognizing endothelial cells of the blood-brain barrier. The Avitag sequence was biotinylated with BirA and the $s c F v$ was successfully conjugated to streptavidin quantum dots [88]. AviTag fusion to an $s c F v$, which binds to the ligand-induced binding site (LIBS) of GPIIb/IIIa ( $\left.\mathrm{scFv}_{\text {anti-LIBS }}\right)$ on activated platelets facili- 
tated conjugation to streptavidin lipid shell-based gasfilled microbubbles for contrast-enhanced ultrasound imaging of thrombus formation in mice carotid arteries [89]. This design allowed real-time monitoring of imaging of thrombolysis, which was further developed as a theranostic approach using the fibrinolytic drug urokinase plasminogen activator linked to microbubbles [90]. Recent studies by Greineder et al. demonstrated efficient binding of cross-species (human and rodent) anti-PECAM-1-specific scFv-AviTag fusion to streptavidin-coated liposomes [91]. PECAM-targeted liposomes were bound and endocytozed by HUVECs under static and flow conditions. Biodistribution studies in rats confirmed targeted delivery to the pulmonary vasculature. Alternatively, biotin-functionalized nanoparticles may be conjugated to recombinant streptavidin fusion proteins. Streptavidin and avidin are tetrameric, and so genetic fusion with antibodies results in multimers. Rhizavidin is a dimeric biotinbinding protein from Rhizobium etli and incorporating its active site residues into streptavidin by rational design has yielded monomeric streptavidin that is more amenable to genetic fusion [92].

\section{Sortase}

Sortase A is a Staphylococcus aureus transpeptidase that cleaves between threonine and glycine in the sequence LPXTG with concomitant formation of a new peptide bond between an N-terminal glycine of another biomolecule or particle [93,94]. Sortase-tag fused $\mathrm{scFv}_{\text {anti-LIBS }}$ and recombinant thrombomodulin also incorporating a sortase-tag have been conjugated to $\mathrm{N}$-terminal triglycine-modified elastin-like peptide micelles to develop a targeted approach for imaging of

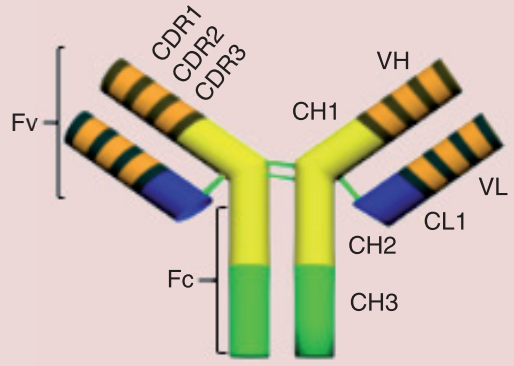

Mouse antibody

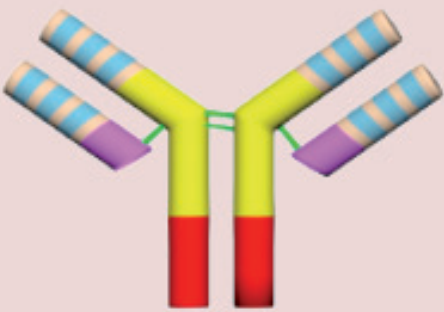

Human antibody

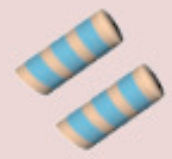

Fv

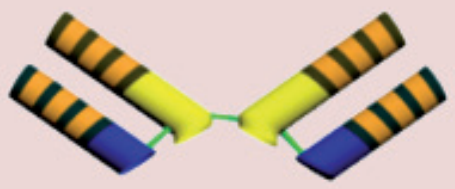

$\mathrm{F}(\mathrm{ab})_{2}$

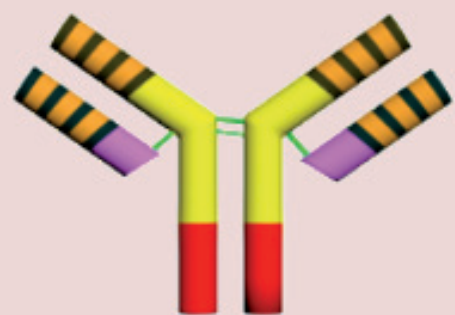

Chimeric antibody

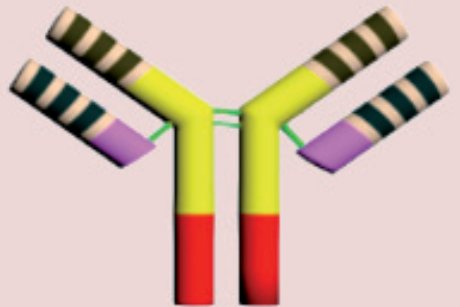

Humanized antibody

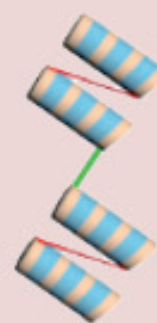

Di-scFv

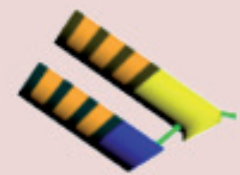

Fab-SH

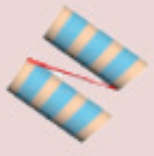

scFv

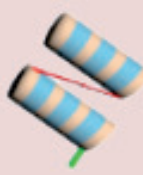

ScFv-SH

Figure 1. Diagrammatic depiction of the structure of various monoclonal antibodies and antibody fragments. Top row: mouse monoclonal antibody depicting variable $(\mathrm{VL}$ and $\mathrm{VH})$ and constant domains $(\mathrm{CH} 3, \mathrm{CH} 2, \mathrm{CH} 1$ and $\mathrm{CL} 1)$ of antibody heavy and light chains including CDRs; structure of $F\left(a b^{\prime}\right)_{2}$ and Fab fragments derived from enzymatic digestion of mouse antibody. Middle row: human antibody and human antibody with mouse variable regions (chimeric antibody) and human antibody with mouse CDR (humanized antibody). Bottom row: recombinant single-chain antibodies (scFvs) incorporating human antibody variable regions with or without a flexible linker (red) or disulfide linkage (green).

CDR: Complementarity-determining region; scFv: Single-chain variable fragment; VH: Variable heavy chain; VL: Variable light chain. 


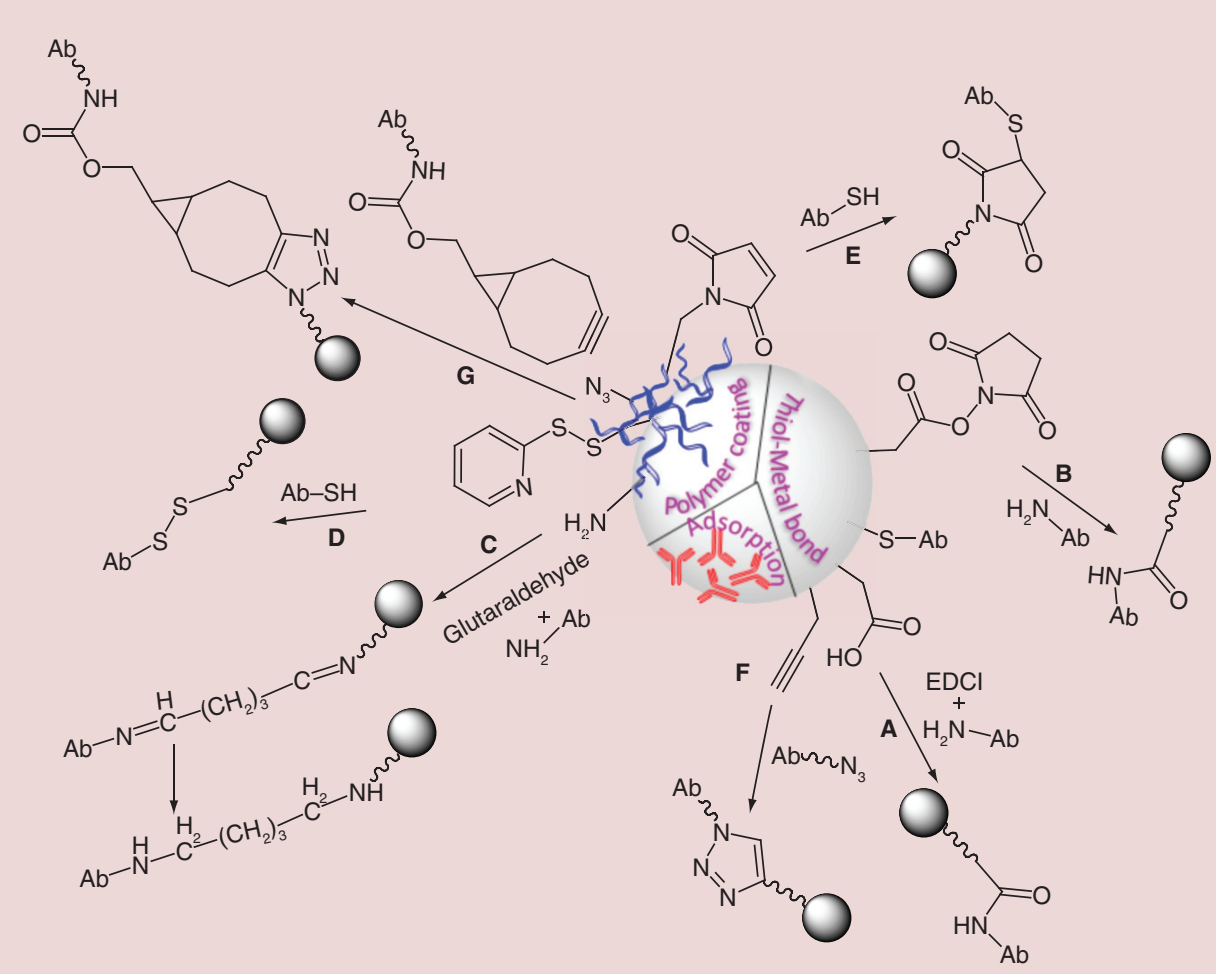

Figure 2. Various strategies for biofunctionalization of a nanoparticle surface. Conjugation via: (A) amide linkage; (B) active ester; (C) Schiff base/amine; (D) disulfide linkage; (E) thioether linkage; (F) CuAAC conjugation; (G) SPAAC conjugation.

CUAAC: Copper-catalyzed azide-alkyne cycloaddition; SPAAC: Strain-promoted azide-alkyne click.

the thrombus and therapeutic strategy for inhibiting thrombus formation in a mouse model of thrombosis [95]. To overcome the need for a sortase enzyme and its removal from the reaction mixture, a single recombinant construct incorporating LPXTG, a $(\mathrm{GGS})_{5}$ linker, SrtA and a His-tag was engineered to the C-terminal of the protein of interest [96]. This strategy combines the purification and bioconjugation into a single step, which entails adding any protein or peptide with an N-terminal (Gly) ${ }_{3}$ and calcium to the immobilized protein on the affinity column. This strategy was used for site-specific introduction of a fluorophore as well as an azide onto an anti-Her2 affibody, which was subsequently linked to azadibenzocyclooctyne-functionalized SPIO using click chemistry. The Her2-targeted SPIO showed a marked decrease in T2-relaxation times when bound to Her2+ cells compared with Her2 ${ }^{-}$cells.

\section{Nanomaterial binding antibodies}

Phage display techniques have allowed identification of peptides that bind various nanomaterials [97]. Incorporation of these peptide domains onto antibody molecules allows site-specific binding onto nanoparticles. A high-affinity, heavy-chain camel antibody incorporating a gold-binding peptide in CDR1 with an optimized CDR3 was produced and fused to another heavy-chain camel antibody with specificity for the EGFR. This bispecific antibody was able to target gold particles to EGFR-positive cells in vitro [98]. Similarly, a high-affinity bispecific antibody was engineered with specificity to gold and hen-eggwhite lysozyme [99].

\section{SH (Sulfhydryl)}

A cysteine engineered on an $\mathrm{scFv}$ is the most commonly used site-specific modification for nanoparticle conjugation. An scFv incorporating a terminal cysteine was linked to maleimide PEG-stabilized SPIO nanoparticles, resulting in targeted nanoparticles that were specific to Her2-expressing BT-474 breast cancer cells with twofold greater uptake than nontargeted particles in vitro [65]. An anti-EGFR scFv based on panitumumab that incorporated a cysteine at the C-terminus was conjugated to a protein nanoparticle with a free cysteine using a bis-maleimide cross-linker retaining specific EGFR-binding activity [66].

\section{His6-tag}

The hexa His-tag frequently fused to recombinant single-chain antibodies to facilitate purification by metalaffinity chromatography has been used as a linker for 
nanoparticle conjugation. Iron oxide nanoparticles coated with poly(isobutylene-alt-maleic anhydride) were reacted with lysine-nitrilotriacetic acid and loaded with $\mathrm{Ni}^{2+}$. A His-tagged anti-Her2 $\mathrm{scFv}$ was conjugated to the particles; however, the binding to MCF7 cells was inferior when compared with a sitespecific scFv linked via a cysteine to the particle [100]. It was suggested that, on a spherical nanoparticle, linkage via a cysteine on the linker between VL and VH positioned the $s c F v$ favorably compared with linkage via a His-tag at the C-terminal. Lo et al. used a His-tagged anticarcinoembryonic antigen $\mathrm{scFv}$ for coating an Nidecorated single-walled carbon nanotube field-effect transistor to develop a biosensor, which outperformed a randomly oriented $\mathrm{scFv}$ conjugated via lysines [101].

\section{N-terminal serine/threonine}

The N-terminal site in antibodies is located distant from the antigen-binding site and so is suitable for site-specific modification. Incorporation of an $\mathrm{N}$-terminal serine or threonine by genetic engineering allows site-specific modification to a reactive group via selective oxidation of the 1,2-amino alcohol to an $\alpha-\mathrm{N}$-glyoxylyl group. The aldehyde group can undergo a facile reaction with hydrazides to form hydrazones. In addition, the aldehyde group can be converted to a nitrone in situ with N-methylhydroxylamine, which can undergo a strain-promoted alkyl nitrone cycloaddition reaction with a strained alkyne-modified nanoparticle [102]. Colombo et al. used DABCO-functionalized magnetic nanocrystals to conjugate $\mathrm{N}$-terminal serine containing anti-Her2 $s c F v$ using the strain-promoted alkyl nitrone cycloaddition reaction. Their studies demonstrated that scFvconjugated nanocrystals retained antigen-binding selectivity and specifically internalized into MCF7 cells. Furthermore, they reported a dose-dependent fall in T2 relaxation [103].

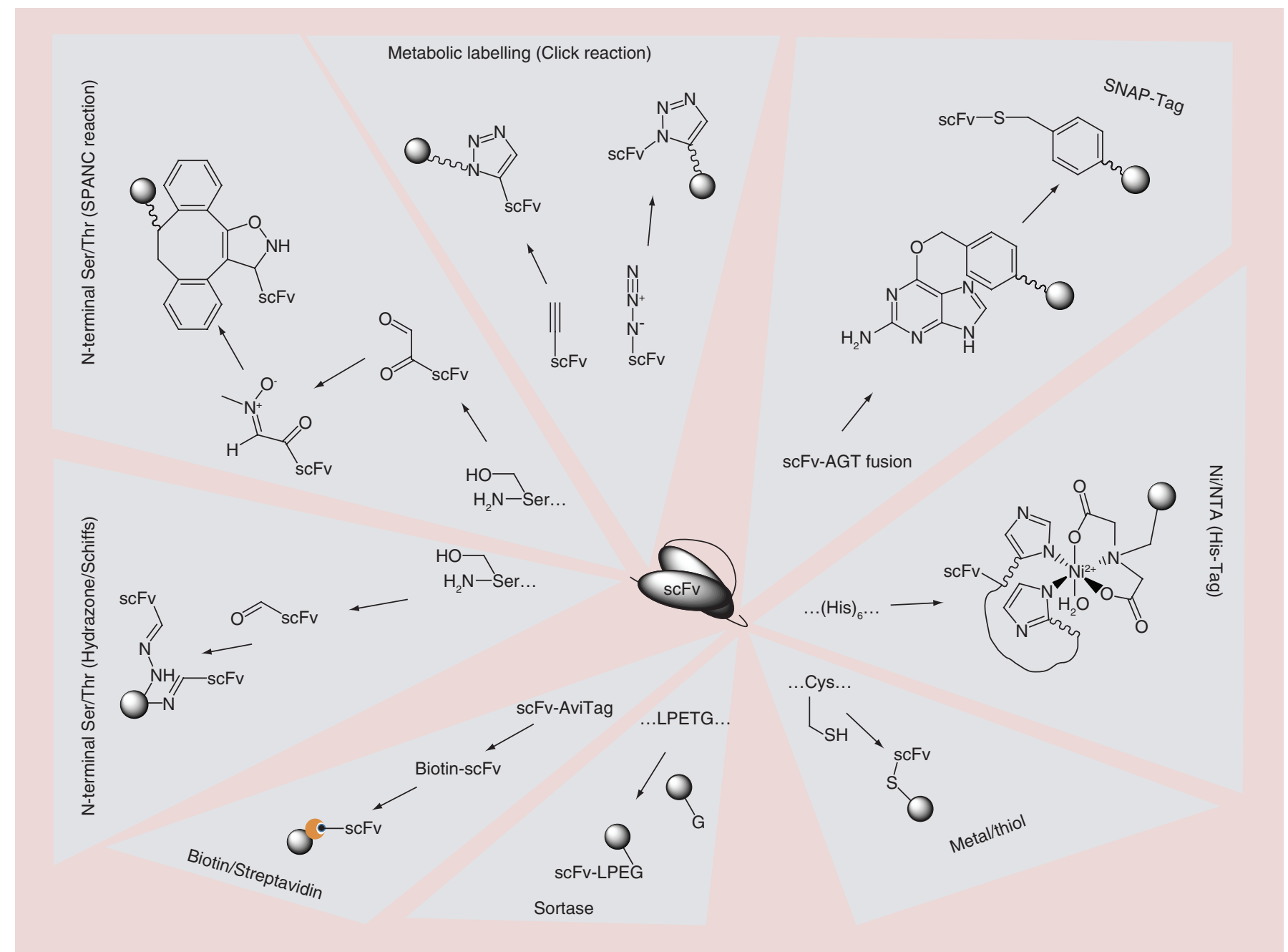

Figure 3. Various strategies for site-specific modification of single-chain antibodies (scFvs). Relevant site of modification (N-terminal, C-terminal or $\mathrm{VL} / \mathrm{VH}$ ) on ScFv is shown with the pointing triangle enclosing the coupling reaction. scFv: Single-chain variable fragment; VH: Variable heavy chain; VL: Variable light chain. 


\section{Enzyme-tag}

The SNAP-tag technology utilizes an enzyme tag that is fused to the antibody. The enzyme fusion protein forms a covalent bond with its substrate ana$\log$, which is linked to the second biomolecule or particle. The human DNA-repaired enzyme O(6)alkylguanine DNA alkyltransferase covalently binds $\mathrm{O}(6)$-benzylguanine substrates via a sulfhydryl group present at the active site of the enzyme [104]. An antiCD30 single-chain antibody fragment fused with the $20 \mathrm{kDa}$ enzyme was site-specifically labeled with different fluorophores and also immobilized onto nanoparticles [105]. Similarly, SNAP-scFv fusion with specificity to $\mathrm{Her} 2$ was linked to $\mathrm{Fe}_{3} \mathrm{O}_{4}$ nanoparticles incorporating surface PEG-guanine molecules. The Her2-targeted particles selectively bound to Her2+ve MCF7 breast cancer cells, but not to Her2-ve MDA cells [106]. Hussain et al. used an EGFR-specific SNAP-tag fusion protein to target a doxorubicinlinked dendritic polyglycerol nanocarrier to selectively kill EGFR+ve cell lines [59]. Halo-tag and CLIP-tag strategies similarly utilized mutant bacterial haloalkane dehalogenase enzyme and an engineered variant of $\mathrm{O}(6)$-alkylguanine DNA alkyltransferase, respectively $[107,108]$.

\section{Genetically encoded amino acids for ligation}

The ability to genetically engineer unnatural amino acids site specifically into an antibody allows elaboration of a multitude of reactive sites for bioorthogonal reactions [109]. Amino acids with azides, alkynes, aldehydes and ketones have been explored [110]. Thus far, these modifications have mainly been explored for labeling strategies; however, they can be readily adapted for site-specific biofunctionalization of nanoparticles.

\section{A case for recombinant antibodies in nanoparticle targeting}

The reliance on passive targeting of nanoparticles based on the EPR effect is inadequate, as there are many factors that affect the EPR effect such as tumor type, intratumoral pressure and vascularization [111,112]. Based on preclinical data, there are a number of alternative ligands other than recombinant antibodies that can be used for active targeting of nanoparticles to tumors. However, the rapidly increasing number of FDA-approved therapeutic antibodies to a variety of validated tumor targets and a couple of ADCs makes antibodies a promising targeting ligand for nanoparticles. It is understandable that the pharmacokinetics and pharmacodynamics of the targeting antibody are modified when linked to the nanoparticle. However, any off-target effects of the antibody will be welldefined. There are a number of important aspects in relation to the active targeting of nanoparticles where recombinant antibodies will provide major benefits:

- Site-specific conjugation or control of orientation of antibody on surface of nanoparticle: as described above, recombinant antibody engineering techniques allow site-specific introduction of single amino acid residues or a sequence of amino acids to enable conjugation to compatible reactive groups introduced onto the nanoparticle surface in a defined optimal orientation without loss of target-binding activity. The most common modification has been the site-specific introduction of a cysteine residue. Several studies (discussed in the previous section) have demonstrated the importance of the control of antibody orientation using in vitro binding assays, but none have compared their performance in vivo [85,100-101]. In an interesting approach, Parolo et al., utilized the fact that negatively charged gold nanoparticle surfaces will form favorably charged interactions with protonated lysine on an antibody at a $\mathrm{pH}$ lower than the isoelectric point of the antibody for orientated bioconjugation with EDCI and sulfo-NHS [113]. Using this method, there was a tenfold improvement of the detection limit in an immunoassay, compared with antibodies randomly orientated on gold nanoparticles;

- Size: even though smaller antibody fragments such as $\mathrm{F}\left(\mathrm{ab}^{\prime}\right)_{2}$ and Fab (Figure 1) can be generated from intact murine antibodies by enzymatic and/or chemical methods for conjugation to nanoparticles, the yields are low and scaling up is tedious. Smaller recombinant antibody entities such as scFvs have several advantages over intact antibodies such as lower immunogenicity, higher specificity, lack of the Fc which is more immunogenic, and nonbinding to Fc receptors and complements. Furthermore, using phage display libraries and mutagenesis, high-affinity binding scFvs can be generated. Recombinant variants of these smaller antibodies can be readily generated at a scale for bioconjugation. There is a paucity of studies comparing the advantage of size of the antibody in nanoparticle efficacy. A single study comparing the pharmacokinetics and biodistribution of a CD19-specific intact antibody, Fab', with scFv-linked doxorubicin-loaded stealth liposomes indicated a longer circulation time and liver uptake for the Fab'-linked liposomes compared with intact immunoglobulin or $\mathrm{scFv}_{\mathrm{f}}$ [114]. The high liver uptake of $\mathrm{scFv}$ was attributed to the presence of a c-myc/poly-his-tag. Groups of mice bearing Raji tumors treated with the Fab'-linked liposome group had more long- 
term survivors. Similar results using Namalwa tumors with another CD19 antibody (FMC63) and Fab' were reported by Sapra et al. [115];

- Affinity: the affinity of the antibody or fragment, once linked to the nanoparticle, may not be too crucial because of the increased avidity of binding due to multivalency. Zhou et al. have shown with immunoliposomes that binding affinity matters only with low-density modifications [116]. However, unlike mouse antibodies generated via the hydridoma technique, high-affinity recombinant antibodies can be readily engineered by screening and mutagenesis;

- Immunogenicity: the immunogenicity of mouse antibodies in humans was the impetus for designing increasingly humanized antibody variants or smaller antigen-binding moieties. Linkage of immunogenic antibodies to nanoparticles would exacerbate immunogenicity due to stimulation of antibody production by B cells and uptake by the reticuloendothelial system as well as antigen-presenting cells. The attachment of PEG chains onto nanoparticles does reduce uptake by macrophages and other cells in the RES by specifically masking the nanoparticle surface, resulting in increased circulation times. However, it should be noted that studies with many types of PEGylated nanoparticles have shown accelerated blood clearance (known as the ABC phenomenon) of nanoparticles on repeat administration due to the formation of anti-PEG-specific immunoglobulin $\mathrm{M}$ antibodies, which could hamper clinical application [117-119]. There have not been any systematic studies on the immunogenicity of mouse or human antibody-linked nanoparticles or small antibody fragments. An interesting study by Yang et al. [120] demonstrated in a mouse model that multiple intravenous or subcutaneous injections of iron oxide nanoparticles linked to an scFv to EGFR isolated from a human naive phage display library (27\% homology to mouse immunoglobulin kappa variable region), a mouse amino-terminal fragment of the receptor-binding domain of urokinase plasminogen activator ( $87 \%$ homology to natural amino-terminal fragment) or mouse serum albumin all induced mouse antibodies to the protein conjugated on the nanoparticle. However, inclusion of a therapeutic payload of doxorubicin attenuated the antibody responses, probably due to the elimination of antigen-specific B cells or antigen-presenting cells. Thus far, there are no reports on the immunogenicity of any ligands attached to nanoparticles in humans.

\section{Conclusion}

There is a myriad of preclinical studies demonstrating antitumor effects with recombinant antibody-targeted therapeutic nanomaterials (Table 1). It is evident that there are definite advantages of using targeted nanoparticles compared with nontargeted particles that are reliant only on localization based on the EPR effect. The achieved enrichment and localized therapeutic effects are due to the specific ligand-mediated uptake of the nanoparticles by receptor-mediated endocytosis, a mechanism absent in naked particles. Even though nonantibody ligands such as folic acid, transferrin and others have been used for active targeting, the high selectivity and the availability of antibodies to some well-validated targets and the FDA approval already given to recombinant antibodies make them an ideal choice.

The ability to engineer novel site specific, conjugatable small-antibody fragments with retained selectivity of the parent antibody also makes a compelling case for antibody ligands [121]. As discussed above, such new small-antibody formats can avoid direct interaction with the RES and so may be less immunogenic in humans. Modification of nanoparticles with PEG and judicial choice of nanoparticle size can further reduce RES uptake and increase blood circulation times. Active targeting will not eliminate accumulation of particles in the liver or spleen. Despite the approval of several nanoparticle compositions and therapeutic antibody and antibody-drug conjugates, thus far there have been no nanoparticle therapeutics with an antibody or nonantibody-targeting ligand approved by the FDA. However, based on the numerous advantages of antibody-targeted nanomedicine, several clinical trials are currently underway [122-124]. Notably, the first ADC incorporating methotrexate linked to a polyclonal antibody was reported by Mathé et al. [125] in 1958, but it took many decades before the first ADC was approved in 2011.

The development of nanoparticles is multifaceted and several hurdles have yet to be overcome, such as production scaling up, consistency in manufacturing and product stability $[126,127]$. However, recombinant production of antibodies and advanced conjugation technologies have substantially accelerated the development of targeted nanotherapeutics. It is likely that the first generation of targeted nanoparticles will be approved in the near future and also likely that these will be made of polymers that have demonstrated good safety profiles in humans and recombinant therapeutic antibodies that have been already approved for human use.

\section{Future perspective}

The ultimate goal of therapies for various diseases is the discovery of Paul Ehrlich's 'magic bullet', an ideal thera- 
peutic agent that kills only the targeted organism, proposed in the late 1800s. With the advent of monoclonal antibody technology, highly specific therapeutic antibodies with either effector function or highly cytotoxic antibody-drug conjugates came close to being 'magic bullets' but were let down by the lack of tumor-specific antigens. The current availability of stable nanoparticles with tailor-made properties to accumulate in tumors via the EPR effect, as well as active targeting, drug release or creation of local hyperthermia with local or external stimuli, opens up a myriad of site specific, for example, cancer-selective, therapeutic modalities.

Currently, the next-generation sequencing of tumors is unveiling the cancer mutanome that is unique in individuals and this opens up the future possibility of using active targeting with recombinant antibodies or neoantigen-loaded nanoparticles for personalized therapy. In the next 5-10 years we will also see targeted nanoparticles being used to deliver checkpoint inhibitors, which are small chemical entities capable of polarizing the tumor microenvironment in order to facilitate tumor elimination via the natural immunosurveillance mechanisms.

The greatest hindrances to rapid clinical translation so far are the scaling up, reproducibility of GMP manufacture, efficient conjugation technologies and stability of nanoparticulate medicines. However, these obstacles have recently been overcome. Also, more and more preclinical models are being developed that create a basis for carefully planned Phase I clinical trials, with GMP products being sufficiently tested in toxicology studies. We will witness whether the nanomedicine lives up to its promise within the near future.

\section{Financial \& competing interests disclosure}

$\mathrm{K}$ Peter was supported by a Principal Research Fellowship from the National Health and Medical Research Council (NHMRC) of Australia. The authors have no other relevant affiliations or financial involvement with any organization or entity with a financial interest in or financial conflict with the subject matter or materials discussed in the manuscript apart from those disclosed.

No writing assistance was utilized in the production of this manuscript.

\section{Open access}

This work is licensed under the Attribution-NonCommercialNoDerivatives 4.0 Unported License. To view a copy of this license, visit http://creativecommons.org/licenses/by-ncnd/4.0/

\section{Executive summary}

\section{Targeting of nanoparticles}

- Therapeutic nanoparticles can be delivered to areas of interest, for example, tumors, by passive targeting or active targeting.

- Passive targeting ultilizes the enhanced permeation and retention effects due to abnormal tumor vasculature, while active targeting utilizes ligands that bind tumor cells and are internalized.

\section{Therapeutic nanoparticles}

- Nanoparticles can be made from various materials - metals, lipids, proteins, carbohydrates, polymers or combinations of these.

- Therapeutic nanoparticles can be used to deliver drugs, proteins, siRNA and microRNA.

- The selectivity of passive targeting can be increased by utilizing stimuli-responsive multifunctional nanoparticles.

- Active targeting has the advantage of target selectivity, accumulation at the tumor site and longer retention of therapeutic nanoparticles.

Conjugation of recombinant antibodies \& fragments to nanoparticles

- Intact mouse and humanized antibodies can be conjugated to reactive groups (amino, carboxylic and sulfhydryl) of antibodies via a variety of methods.

- Recombinant antibody fragments are ideal for active targeting due to their size, lower immunogenicity and ability to be conjugated with optimum orientation using site-specific engineering of reactive cysteines, nonnatural amino acids, enzyme domains or enzyme-specific substrate sequences.

- Preclinical studies of active-targeted nanoparticles have demonstrated greater therapeutic efficacy than passively accumulated nanoparticles.

\section{References}

1 Etheridge ML, Campbell SA, Erdman AG, Haynes CL, Wolf SM, McCullough J. The big picture on nanomedicine: the state of investigational and approved nanomedicine products. Nanomedicine 9(1), 1-14 (2013).
2 Doane TL, Burda C. The unique role of nanoparticles in nanomedicine: imaging, drug delivery and therapy. Chem. Soc. Rev. 41(7), 2885-2911 (2012).

3 Petschauer JS, Madden AJ, Kirschbrown WP, Song G, Zamboni WC. The effects of nanoparticle drug loading on 
the pharmacokinetics of anticancer agents. Nanomedicine (Lond.) 10(3), 447-463 (2015).

4 Sadat SMA, Jahan ST, Haddadi A. Effects of size and surface charge of polymeric nanoparticles on in vitro and in vivo applications. J. Biomater. Nanobiotechnol. 7, 91-108 (2016).

5 Blanco E, Shen H, Ferrari M. Principles of nanoparticle design for overcoming biological barriers to drug delivery. Nat. Biotechnol. 33(9), 941-951 (2015).

6 Longmire M, Choyke PL, Kobayashi H. Clearance properties of nano-sized particles and molecules as imaging agents: considerations and caveats. Nanomedicine (Lond.) 3(5), 703-717 (2008).

7 Mody VV, Siwale R, Singh A, Mody HR. Introduction to metallic nanoparticles. J. Pharm. Bioallied Sci. 2(4), 282-289 (2010).

8 Lima-Tenorio MK, Pineda EA, Ahmad NM, Fessi H, Elaissari A. Magnetic nanoparticles: in vivo cancer diagnosis and therapy. Int. J. Pharm. 493(1-2), 313-327 (2015).

9 Bilan R, Nabiev I, Sukhanova A. Quantum dot-based nanotools for bioimaging, diagnostics, and drug delivery. Chembiochem 17(22), 2103-2114 (2016).

10 Yang Y, Yu C. Advances in silica based nanoparticles for targeted cancer therapy. Nanomedicine 12(2), 317-332 (2016).

11 Banik BL, Fattahi P, Brown JL. Polymeric nanoparticles: the future of nanomedicine. Wiley Interdiscip. Rev. Nanomed. Nanobiotechnol. 8(2), 271-299 (2016).

12 Bharali DJ, Khalil M, Gurbuz M, Simone TM, Mousa SA. Nanoparticles and cancer therapy: a concise review with emphasis on dendrimers. Int. J. Nanomedicine 4, 1-7 (2009).

13 Li F, Zheng C, Xin J et al. Enhanced tumor delivery and antitumor response of doxorubicin-loaded albumin nanoparticles formulated based on a Schiff base. Int. J. Nanomedicine 11 3875-3890 (2016).

14 Zhai J, Scoble JA, Li N et al. Epidermal growth factor receptor-targeted lipid nanoparticles retain self-assembled nanostructures and provide high specificity. Nanoscale 7(7), 2905-2913 (2015).

15 Zhang Y, Petibone D, Xu Y et al. Toxicity and efficacy of carbon nanotubes and graphene: the utility of carbon-based nanoparticles in nanomedicine. Drug Metab. Rev. 46(2), 232-246 (2014).

16 Prabaharan M. Chitosan-based nanoparticles for tumortargeted drug delivery. Int. J. Biol. Macromol. 72, 1313-1322 (2015).

17 Weissig V, Pettinger TK, Murdock N. Nanopharmaceuticals (part 1): products on the market. Int. J. Nanomedicine 9, 4357-4373 (2014).

18 Weissig V, Guzman-Villanueva D. Nanopharmaceuticals (part 2): products in the pipeline. Int. J. Nanomedicine 10, 1245-1257 (2015).

19 Greish K. Enhanced permeability and retention of macromolecular drugs in solid tumors: a royal gate for targeted anticancer nanomedicines. J. Drug Target 15(7-8), 457-464 (2007)

20 Coulie PG, Van den Eynde BJ, van der Bruggen P, Boon T. Tumour antigens recognized by $\mathrm{T}$ lymphocytes: at the core of cancer immunotherapy. Nat. Rev. Cancer 14(2), 135-146 (2014).

21 Vigneron N. Human tumor antigens and cancer immunotherapy. Biomed. Res. Int. 2015 , 948501 (2015).

22 Jo H, Ban C. Aptamer-nanoparticle complexes as powerful diagnostic and therapeutic tools. Exp. Mol. Med. 48, e230 (2016).

23 Yao VJ, D’angelo S, Butler KS et al. Ligand-targeted theranostic nanomedicines against cancer. J. Control. Release 240, 267-286 (2016).

24 Elias A, Crayton SH, Warden-Rothman R, Tsourkas A. Quantitative comparison of tumor delivery for multiple targeted nanoparticles simultaneously by multiplex ICP-MS Sci. Rep. 4, 5840 (2014).

25 Gilad Y, Firer MA, Gellerman G. Recent innovations in peptide based targeted drug delivery to cancer cells. Biomedicines 4(2), pii:E11 (2016).

26 Chuang EY, Lin CC, Chen KJ et al. A FRET-guided, NIR-responsive bubble-generating liposomal system for in vivo targeted therapy with spatially and temporally precise controlled release. Biomaterials 93, 48-59 (2016).

27 Muntimadugu E, Kumar R, Saladi S, Rafeeqi TA, Khan W. CD44 targeted chemotherapy for co-eradication of breast cancer stem cells and cancer cells using polymeric nanoparticles of salinomycin and paclitaxel. Colloids Surf. $B$ Biointerfaces 143, 532-546 (2016).

28 Perez-Herrero E, Fernandez-Medarde A. Advanced targeted therapies in cancer: drug nanocarriers, the future of chemotherapy. Eur. J. Pharm. Biopharm. 93, 52-79 (2015).

29 Ashton S, Song YH, Nolan J et al. Aurora kinase inhibitor nanoparticles target tumors with favorable therapeutic index in vivo. Sci. Transl. Med. 8(325), 325 ra317 (2016).

30 Chen Y, Zhu X, Zhang X, Liu B, Huang L. Nanoparticles modified with tumor-targeting scFv deliver siRNA and miRNA for cancer therapy. Mol. Ther. 18(9), 1650-1656 (2010).

31 Singh MS, Peer D. RNA nanomedicines: the next generation drugs? Curr. Opin. Biotechnol. 39, 28-34 (2016).

32 Young SW, Stenzel M, Yang JL. Nanoparticle-siRNA: a potential cancer therapy? Crit. Rev. Oncol. Hematol. 98, 159-169 (2016).

33 Zatsepin TS, Kotelevtsev YV, Koteliansky V. Lipid nanoparticles for targeted siRNA delivery - going from bench to bedside. Int. J. Nanomedicine 11, 3077-3086 (2016).

34 Ma D. Enhancing endosomal escape for nanoparticle mediated siRNA delivery. Nanoscale 6(12), 6415-6425 (2014).

35 Li W, Wei H, Li H, Gao J, Feng SS, Guo Y. Cancer nanoimmunotherapy using advanced pharmaceutical nanotechnology. Nanomedicine (Lond.) 9(16), 2587-2605 (2014).

36 Toy R, Roy K. Engineering nanoparticles to overcome barriers to immunotherapy. Bioeng. Transl. Med. 1, 16 (2016).

37 Kwon YJ, James E, Shastri N, Frechet JM. In vivo targeting of dendritic cells for activation of cellular immunity using 
vaccine carriers based on $\mathrm{pH}$-responsive microparticles. Proc. Natl Acad. Sci. USA 102(51), 18264-18268 (2005).

Sehgal K, Dhodapkar KM, Dhodapkar MV. Targeting human dendritic cells in situ to improve vaccines. Immunol. Lett. 162(1 Pt A), 59-67 (2014).

Gutjahr A, Phelip C, Coolen AL et al. Biodegradable polymeric nanoparticles-based vaccine adjuvants for lymph nodes targeting. Vaccines 4(4), pii:E34 (2016).

A, Guduru R, Liang Pet al. Targeted and controlled anticancer drug delivery and release with magnetoelectric nanoparticles. Sci. Rep. 6, 20867 (2016).

41 Liu Q, Zhan C, Kohane DS. Phototriggered drug delivery using inorganic nanomaterials. Bioconjug. Chem. 28(1), 98-104 (2016).

42 Zou L, Wang H, He B et al. Current approaches of photothermal therapy in treating cancer metastasis with nanotherapeutics. Theranostics 6(6), 762-772 (2016).

43 Arunkumar P, Raju B, Vasantharaja R et al. Near infrared laser mediated photothermal and antitumor efficacy of doxorubicin conjugated gold nanorods with reduced cardiotoxicity in Swiss albino mice. Nanomedicine 11(6), 1435-1444 (2015).

44 Mura S, Nicolas J, Couvreur P. Stimuli-responsive nanocarriers for drug delivery. Nat. Mater. 12(11), 991-1003 (2013).

45 Cheng YJ, Luo GF, Zhu JY et al. Enzyme-induced and tumor-targeted drug delivery system based on multifunctional mesoporous silica nanoparticles. ACS Appl. Mater. Interfaces 7(17), 9078-9087 (2015).

46 Satsangi A, Roy SS, Satsangi RK et al. Synthesis of a novel, sequentially active-targeted drug delivery nanoplatform for breast cancer therapy. Biomaterials 59, 88-101 (2015).

47 Tian L, Lu L, Qiao Y, Ravi S, Salatan F, Melancon MP. Stimuli-responsive gold nanoparticles for cancer diagnosis and therapy. J. Funct. Biomater. 7(3), pii:E19 (2016).

48 Li HJ, Du JZ, Du XJ et al. Stimuli-responsive clustered nanoparticles for improved tumor penetration and therapeutic efficacy. Proc. Natl Acad. Sci. USA 113(15), 4164-4169 (2016).

49 An X, Zhu A, Luo H, Ke H, Chen H, Zhao Y. Rational design of multi-stimuli-responsive nanoparticles for precise cancer therapy. ACS Nano 10 (6), 5947-5958 (2016).

50 Liu Y, Feng L, Liu T et al. Multifunctional pH-sensitive polymeric nanoparticles for theranostics evaluated experimentally in cancer. Nanoscale 6(6), 3231-3242 (2014).

51 Jin H, Liu X, Gui R, Wang Z. Facile synthesis of gold nanorods/hydrogels core/shell nanospheres for $\mathrm{pH}$ and near-infrared-light induced release of 5-fluorouracil and chemo-photothermal therapy. Colloids Surf. B Biointerfaces $128,498-505$ (2015).

52 Crayton SH, Elias DR, Al Zaki A, Cheng Z, Tsourkas A. ICP-MS analysis of lanthanide-doped nanoparticles as a nonradiative, multiplex approach to quantify biodistribution and blood clearance. Biomaterials 33(5), 1509-1519 (2012).

53 Pirollo KF, Chang EH. Does a targeting ligand influence nanoparticle tumor localization or uptake? Trends Biotechnol. 26(10), 552-558 (2008).
54 Wilhelm S, Tavares AJ, Dai Q et al. Analysis of nanoparticle delivery to tumours. Nat. Rev. Mat. 1, 12 (2016).

55 Huwyler J, Cerletti A, Fricker G, Eberle AN, Drewe J. Bypassing of P-glycoprotein using immunoliposomes. J. Drug Target 10(1), 73-79 (2002).

56 Taylor K, Howard CB, Jones ML et al. Nanocell targeting using engineered bispecific antibodies. MAbs 7(1), 53-65 (2015).

57 Quarta A, Bernareggi D, Benigni F et al. Targeting FRexpressing cells in ovarian cancer with Fab-functionalized nanoparticles: a full study to provide the proof of principle from in vitro to in vivo. Nanoscale 7(6), 2336-2351 (2015).

58 Zhao M, Liu Y, Hsieh RS et al. Clickable protein nanocapsules for targeted delivery of recombinant $\mathrm{p} 53$ protein. J. Am. Chem. Soc. 136(43), 15319-15325 (2014).

59 Hussain AF, Kruger HR, Kampmeier F et al. Targeted delivery of dendritic polyglycerol-doxorubicin conjugates by $s c F v-S N A P$ fusion protein suppresses EGFR + cancer cell growth. Biomacromolecules 14(8), 2510-2520 (2013).

60 Van de Broek B, Devoogdt N, D'hollander A et al. Specific cell targeting with nanobody conjugated branched gold nanoparticles for photothermal therapy. ACS Nano 5(6), 4319-4328 (2011).

61 Goodall S, Munro TP, Howard CB et al. An EGFR targeting nanoparticle self assembled from a thermoresponsive polymer. J. Chem. Technol. Biotechnol. 908 (2015).

62 Nevala WK, Buhrow SA, Knauer DJ, Reid JM, Atanasova EA, Markovic SN. Antibody-targeted chemotherapy for the treatment of melanoma. Cancer Res. 76(13), 3954-3964 (2016).

63 Saeed M, Van Brakel M, Zalba S et al. Targeting melanoma with immunoliposomes coupled to anti-MAGE A1 TCR-like single-chain antibody. Int. J. Nanomedicine 11, 955-975 (2016).

64 Delalat B, Sheppard VC, Rasi Ghaemi S et al. Targeted drug delivery using genetically engineered diatom biosilica. Nat. Commun. 6, 8791 (2015).

65 Alric C, Aubrey N, Allard-Vannier E et al. Covalent conjugation of cysteine-engineered scFv to PEGylated magnetic nanoprobes for immunotargeting of breast cancer cells. RSC Adv. 6, 11 (2016).

66 Buecheler JW, Howard CB, De Bakker CJ et al. Development of a protein nanoparticle platform for targeting EGFR expressing cancer cells. J. Chem. Technol. Biotechnol. 90, 7 (2014).

67 Huang X, Yi C, Fan Y et al. Magnetic $\mathrm{Fe}_{3} \mathrm{O}_{4}$ nanoparticles grafted with single-chain antibody $(\mathrm{scFv})$ and docetaxel loaded $\beta$-cyclodextrin potential for ovarian cancer dual-targeting therapy. Mater. Sci. Eng. C 42, 325-332 (2014)

68 Xiangbao $\mathrm{Y}$, Linquan W, Mingwen $\mathrm{H}$ et al. Humanized antiVEGFR-2 ScFv-As2O3-stealth nanoparticles, an antibody conjugate with potent and selective anti-hepatocellular carcinoma activity. Biomed. Pharmacother. 68(5), 597-602 (2014).

69 Zeng L, Li J, Li J et al. Effective suppression of the Kirsten rat sarcoma viral oncogene in pancreatic tumor cells via 
targeted small interfering RNA delivery using nanoparticles. Pancreas 44(2), 250-259 (2015).

70 Dou S, Yang X-Z, Xiong M-H et al. ScFv-decorated PEGPLA-based nanoparticles for enhanced siRNA delivery to Her2+ breast cancer. Adv. Healthc. Mater. 3, 12 (2014).

71 Qian C, Wang Y, Chen Y et al. Suppression of pancreatic tumor growth by targeted arsenic delivery with anti-CD44v6 single chain antibody conjugated nanoparticles. Biomaterials 34(26), 6175-6184 (2013).

72 Lu RM, Chang YL, Chen MS, Wu HC. Single chain anti-cMet antibody conjugated nanoparticles for in vivo tumortargeted imaging and drug delivery. Biomaterials 32(12), 3265-3274 (2011).

73 Peng XH, Wang Y, Huang D et al. Targeted delivery of cisplatin to lung cancer using ScFvEGFR-heparin-cisplatin nanoparticles. ACS Nano 5(12), 9480-9493 (2011).

74 Chiu ML, Gilliland GL. Engineering antibody therapeutics. Curr. Opin. Struct. Biol. 38, 163-173 (2016).

75 Ridker PM, Revkin J, Amarenco P et al. Cardiovascular efficacy and safety of bococizumab in high-risk patients. N. Engl. J. Med. 376, 1527-1539 (2017).

76 Sabatine MS, Giugliano RP, Keech AC et al. Evolocumab and clinical outcomes in patients with cardiovascular disease. N. Engl. J. Med. 376, 1527-1539 (2017).

77 Frenzel A, Schirrmann T, Hust M. Phage display-derived human antibodies in clinical development and therapy. MAbs 8(7), 1177-1194 (2016).

78 Reichert JM. Antibodies to watch in 2016. MAbs 8(2), 197-204 (2016).

79 Hogarth PM, Pietersz GA. Fc receptor-targeted therapies for the treatment of inflammation, cancer and beyond. Nat. Rev. Drug Discov. 11(4), 311-331 (2012).

80 Kalkanidis M, Pietersz GA, Xiang SD et al. Methods for nano-particle based vaccine formulation and evaluation of their immunogenicity. Methods 40(1), 20-29 (2006).

81 Bartczak D, Kanaras AG. Preparation of peptidefunctionalized gold nanoparticles using one pot EDC/sulfoNHS coupling. Langmuir 27(16), 10119-10123 (2011).

82 Aggarwal S, Gupta S, Pabla D, Murthy RS. Gemcitabineloaded PLGA-PEG immunonanoparticles for targeted chemotherapy of pancreatic cancer. Cancer Nanotechnol. 4(6), 145-157 (2013).

83 Joshi PP, Yoon SJ, Hardin WG, Emelianov S, Sokolov KV. Conjugation of antibodies to gold nanorods through $\mathrm{FC}$ portion: synthesis and molecular specific imaging. Bioconjug. Chem. 24(6), 878-888 (2013).

84 Kumar S, Aaron J, Sokolov K. Directional conjugation of antibodies to nanoparticles for synthesis of multiplexed optical contrast agents with both delivery and targeting moieties. Nat. Protoc. 3(2), 314-320 (2008).

85 Jeong S, Park JY, Cha MG et al. Highly robust and optimized conjugation of antibodies to nanoparticles using quantitatively validated protocols. Nanoscale 9 (7), 2548-2555 (2017).

86 Finetti C, Sola L, Pezzullo M et al. Click chemistry immobilization of antibodies on polymer coated gold nanoparticles. Langmuir 32(29), 7435-7441 (2016).
87 Chen Y, Xianyu Y, Wu J, Yin B, Jiang X. Click chemistrymediated nanosensors for biochemical assays. Theranostics 6(7), 969-985 (2016).

88 Zhang X, Wang XX, Shusta EV. Creation and evaluation of a single-chain antibody tetramer that targets brain endothelial cells. AIChE J. 60(4), 1245-1252 (2014).

89 Wang X, Hagemeyer CE, Hohmann JD et al. Novel single-chain antibody-targeted microbubbles for molecular ultrasound imaging of thrombosis: validation of a unique noninvasive method for rapid and sensitive detection of thrombi and monitoring of success or failure of thrombolysis in mice. Circulation 125(25), 3117-3126 (2012).

90 Wang X, Gkanatsas Y, Palasubramaniam J et al. Thrombustargeted theranostic microbubbles: a new technology towards concurrent rapid ultrasound diagnosis and bleeding-free fibrinolytic treatment of thrombosis. Theranostics 6(5), 726-738 (2016).

91 Greineder CF, Hood ED, Yao A et al. Molecular engineering of high affinity single-chain antibody fragment for endothelial targeting of proteins and nanocarriers in rodents and humans. J. Control. Release 226, 229-237 (2016).

92 Lim KH, Huang H, Pralle A, Park S. Stable, high-affinity streptavidin monomer for protein labeling and monovalent biotin detection. Biotechnol. Bioeng. 110(1), 57-67 (2013).

93 Popp MW, Ploegh HL. Making and breaking peptide bonds: protein engineering using sortase. Angew. Chem. Int. Ed. Engl. 50(22), 5024-5032 (2011).

94 Theile CS, Witte MD, Blom AE, Kundrat L, Ploegh HL, Guimaraes CP. Site-specific N-terminal labeling of proteins using sortase-mediated reactions. Nat. Protoc. 8(9), 1800-1807 (2013).

95 Kim W, Haller C, Dai E et al. Targeted antithrombotic protein micelles. Angew. Chem. Int. Ed. Engl. 54(5), 1461-1465 (2015).

96 Warden-Rothman R, Caturegli I, Popik V, Tsourkas A. Sortase-tag expressed protein ligation: combining protein purification and site-specific bioconjugation into a single step. Anal. Chem. 85(22), 11090-11097 (2013).

97 Sarikaya M, Tamerler C, Jen AK, Schulten K, Baneyx F. Molecular biomimetics: nanotechnology through biology. Nat. Mater. 2(9), 577-585 (2003).

98 Hattori T, Umetsu M, Nakanishi T et al. A high-affinity gold-binding camel antibody: antibody engineering for onepot functionalization of gold nanoparticles as biointerface molecules. Bioconjug. Chem. 23(9), 1934-1944 (2012).

99 Watanabe H, Nakanishi T, Umetsu M, Kumagai I. Human anti-gold antibodies: biofunctionalization of gold nanoparticles and surfaces with anti-gold antibodies. J. Biol. Chem. 283(51), 36031-36038 (2008).

100 Mazzucchelli S, Tortora P, Sommaruga S et al. Dependence of nanoparticle-cell recognition efficiency on the surface orientation of scFv targeting ligands. Biomater. Sci. 1, 9 (2013).

101 Lo YS, Nam DH, So HM et al. Oriented immobilization of antibody fragments on $\mathrm{Ni}$-decorated single-walled carbon nanotube devices. ACS Nano 3(11), 3649-3655 (2009). 
102 Ning X, Temming RP, Dommerholt J et al. Protein modification by strain-promoted alkyne-nitrone cycloaddition. Angew. Chem. Int. Ed. Engl. 49(17), 3065-3068 (2010).

103 Colombo M, Sommaruga S, Mazzucchelli S et al. Sitespecific conjugation of $\mathrm{ScFvs}$ antibodies to nanoparticles by bioorthogonal strain-promoted alkyne-nitrone cycloaddition. Angew. Chem. Int. Ed. Engl. 51(2), 496-499 (2012).

104 Kindermann M, George N, Johnsson N, Johnsson K. Covalent and selective immobilization of fusion proteins. J. Am. Chem. Soc. 125(26), 7810-7811 (2003).

105 Kampmeier F, Ribbert M, Nachreiner T et al. Site-specific, covalent labeling of recombinant antibody fragments via fusion to an engineered version of 6-O-alkylguanine DNA alkyltransferase. Bioconjug. Chem. 20(5), 1010-1015 (2009).

106 Colombo M, Mazzucchelli S, Montenegro JM et al. Protein oriented ligation on nanoparticles exploiting O6alkylguanine-DNA transferase (SNAP) genetically encoded fusion. Small 8(10), 1492-1497 (2012).

107 England CG, Luo H, Cai W. HaloTag technology: a versatile platform for biomedical applications. Bioconjug. Chem. 26(6), 975-986 (2015).

108 Gautier A, Juillerat A, Heinis C et al. An engineered protein tag for multiprotein labeling in living cells. Chem. Biol. 15(2), 128-136 (2008).

109 Spicer CD, Davis BG. Selective chemical protein modification. Nat. Commun. 5, 4740 (2014).

110 Lim SI, Kwon I. Bioconjugation of therapeutic proteins and enzymes using the expanded set of genetically encoded amino acids. Crit. Rev. Biotechnol. 36(5), 803-815 (2016).

111 Danhier F. To exploit the tumor microenvironment: since the EPR effect fails in the clinic, what is the future of nanomedicine? J. Control. Release 244(Pt A), 108-121 (2016).

112 Kobayashi H, Watanabe R, Choyke PL. Improving conventional enhanced permeability and retention (EPR) effects; what is the appropriate target? Theranostics 4(1), 81-89 (2013).

113 Parolo C, De La Escosura-Muniz A, Polo E, Grazu V, De La Fuente JM, Merkoci A. Design, preparation, and evaluation of a fixed-orientation antibody/gold-nanoparticle conjugate as an immunosensing label. ACS Appl. Mater. Interfaces 5(21), 10753-10759 (2013).

114 Cheng WW, Allen TM. Targeted delivery of anti-CD19 liposomal doxorubicin in B-cell lymphoma: a comparison of whole monoclonal antibody, $\mathrm{Fab}^{\prime}$ fragments and single chain Fv. J. Control. Release 126(1), 50-58 (2008).

115 Sapra P, Moase EH, Ma J, Allen TM. Improved therapeutic responses in a xenograft model of human B lymphoma (Namalwa) for liposomal vincristine versus liposomal doxorubicin targeted via anti-CD19 IgG2a or Fab' fragments. Clin. Cancer Res. 10(3), 1100-1111 (2004).

116 Zhou Y, Drummond DC, Zou H et al. Impact of singlechain Fv antibody fragment affinity on nanoparticle targeting of epidermal growth factor receptor-expressing tumor cells. J. Mol. Biol. 371(4), 934-947 (2007).

117 Abu Lila AS, Kiwada H, Ishida T. The accelerated blood clearance $(\mathrm{ABC})$ phenomenon: clinical challenge and approaches to manage. J. Control. Release 172(1), 38-47 (2013).

118 Abu Lila AS, Nawata K, Shimizu T, Ishida T, Kiwada H. Use of polyglycerol (PG), instead of polyethylene glycol (PEG), prevents induction of the accelerated blood clearance phenomenon against long-circulating liposomes upon repeated administration. Int. J. Pharm. 456(1), 235-242 (2013).

119 Hara E, Ueda M, Makino A, Hara I, Ozeki E, Kimura S. Factors influencing in vivo disposition of polymeric micelles on multiple administrations. ACS Med. Chem. Lett. 5(8), 873-877 (2014).

120 Yang E, Qian W, Cao Z et al. Theranostic nanoparticles carrying doxorubicin attenuate targeting ligand specific antibody responses following systemic delivery. Theranostics 5(1), 43-61 (2015).

121 Zhang K, Geddie ML, Kohli N et al. Comprehensive optimization of a single-chain variable domain antibody fragment as a targeting ligand for a cytotoxic nanoparticle. MAbs 7(1), 42-52 (2015).

122 van der Meel R, Vehmeijer LJ, Kok RJ, Storm G, van Gaal EV. Ligand-targeted particulate nanomedicines undergoing clinical evaluation: current status. Adv. Drug Deliv. Rev. 65(10), 1284-1298 (2013).

123 Miller K, Cortes J, Hurvitz SA et al. HERMIONE: a randomized Phase II trial of MM-302 plus trastuzumab versus chemotherapy of physician's choice plus trastuzumab in patients with previously treated, anthracycline-naive, HER2-positive, locally advanced/metastatic breast cancer. BMC Cancer 16, 352 (2016).

124 Anselmo AC, Mitragotri S. Nanoparticles in the clinic. Bioeng. Transl. Med. 1, 20 (2016).

125 Mathé G, Loc TB, Bernard J. Effet sur la Lcucémie 1210 de la souris d'une combinatson par diazotation d'Améthopterine ct de -globulins de hamsters porteurs de cette leucémic par hétérogreffe. C.R. Acad. Sci. Paris 246, 3 (1958).

126 Korsmeyer R. Critical questions in development of targeted nanoparticle therapeutics. Regen. Biomater. 3(2), 143-147 (2016).

127 Landesman-Milo D, Peer D. Transforming nanomedicines from lab scale production to novel clinical modality. Bioconjug. Chem. 27(4), 855-862 (2016). 